\title{
КИНЕМАТИЧЕСКИЕ ПАРАМЕТРЫ ТЕХНИКИ СОЗДАНИЯ ВРАЩЕНИЯ ВОКРУГ ПОПЕРЕЧНОЙ ОСИ В ПРЫЖКАХ В ВОДУ І-ІІІ КЛАССА
}

\section{KINEMATIC PARAMETERS OF TECHNIQUE FOR CREATION OF ROTATION AROUND TRANSVERSE AXIS IN DIVING OF I-III CLASS}

\section{E. Konopleva}

Summary: All motor actions performed by athletes in various sports are analyzed. Changes of position of moving body or its parts relative to other bodies are analyzed [1]. In complex coordination sports, one of the main characteristics of sports is the technique of performing motor actions. However, research aimed at studying the kinematic characteristics of diving technology is not enough. The study of the technique is mainly reduced to a description of the movements of athletes when performing a particular phase of the jump $[2,3]$. In this regard, our study is devoted to the study of the kinematic characteristics of creating the rotation of a body around a transverse axis from a springboard to perform jumps of I and III classes.

Keywords: technique, kinematic characteristics, diving, body rotation, difficult coordination sports.

\author{
Коноплева Елена Николаевна \\ К.п.н., дочент, Сибирский государственный университет \\ науки и технологий имени М.Ф. Решетнева \\ coach@mail.ru
}

Аннотация: Все двигательные действия, выполняемые спортсменами в различных видах спорта, подвергаются анализу. При этом анализируются изменения положения движущегося тела или его частей относительно других тел [1]. В сложно координационных видах спорта одной из основных характеристик спортивной деятельности является техника выполнения двигательных действий. Однако, исследований направленных на изучение кинематических характеристик техники прыжков в воду недостаточно. Изучение техники сводится в основном к описанию движений спортсменов при выполнении той или иной фазы прыжка [2,3]. В связи с этим наше исследование посвящено изучению кинематических характеристик создания вращения тела вокруг поперечной оси с трамплина для выполнения прыжков I и III классов.

Ключевые слова: техника, кинематические характеристики, прыжки в воду, вращение тела, сложно координационные виды спорта.

поступательное движения тела вверх.

Всякое движение возникает под действием внешней силы или нескольких сил, действий которых может быть заменено одной равнодействующей силой, величину которой может определить геометрическим сложением сил. Однако не всякая система сил может быть заменена только равнодействующей силой. Для этого необходимо, чтобы линии действия всех сил пересекались в одной точке. Если же направление сил не пересекается в одной точке, то кроме равнодействующей создается пара сил, которая вызывает вращение тела. Парой сил называется две не лежащие на одной прямой, равные по величине, но противоположно направление силы. Создаваемое парой сил вращение не сопровождается перемещением центра массы в пространстве, тело будет перемещаться в пространстве в направлении равнодействующей сил реакции опоры.

Действия пары сил количественно определятся моментом пары М, то есть произведением величины одной из сил $\mathrm{F}$ на кратчайшее расстояние между направлением их действий, называемой «плечом» силы-r: 


$$
M=F \cdot r
$$

Результат действия пары сил на тело зависит не только от величины его массы, но и от того, как отдельные части массы этого тела расположены относительно центра или оси вращения. Поэтому физической характеристикой тела I, представляющий собой сумму произведений элементарных частей его массы $\mathrm{m}$ на квадрат расстояния r от оси вращения:

$$
I=\sum m \cdot r^{2}
$$

В процессе отталкивание прыгун находится под действием многих сил. Для того что бы определить результат их действий, силы скалываются, используя правило параллелограмма и приема приложений в любых нужных точках тела равных, но противоположно направленных сил.

В процессе отталкивание прыгун находится под действием многих сил. Для того что бы определить результат их действий, силы скалываются, используя правило параллелограмма и приема приложений в любых нужных точках тела равных, но противоположно направленных сил.

Расположение ОЦМ относительно равнодействующей сил реакции опоры в процессе отталкивание определяет возможность или невозможность возникновения вращения тела в ту или иную сторону. Рассмотрим, как в результате действий сил, создаваемых прыгуном при отталкивании, возникает поступательное движение вверх и в сторону бассейна, а также вращательное вокруг поперечной оси.

Оторвавшись от опоры, спортсмен - прыгун в воду попадает в новые условия выполнения движений. Основное их отличие заключается в том, что отсутствие опоры делает невозможным использование внешних сил реакции опоры. Единственной внешней силой, воздействующей на тело, остаётся сила земного притяжения, которая неминуемо направит тело вниз к земле или, вернее сказать, к поверхности воды.

Действия сил земного притяжения на тело спортсмена- прыгуна в воду на опоре и в полете приводит к различным результатам. На опоре силы земного притяжения проявляются как сила веса тела спортсмена. После отрыва от опоры тело прыгуна в воду по инерции движется вверх и от опоры. Инерционным силам движения вверх противодействует силы земного тяготения. Поэтому прыгун взлетает на определенную высоту называемой высотой взлета. Пока тело движется вверх, действие вертикально направленных инерционных сил непрерывно уменьшается, а в верхней точке траектории полета прекращается совсем. Этот момент совпадает с наступлением состояние, близкого к состоянию невесомости. Достигается оно не за счет отсутствия сил тяготения, а за счет уравновешивания их с инерционными силами отталкивания. Именно поэтому в верхней точке траектории полета спортсмен легче всего меняет положение отдельных частей тела меньшей затраты сил, чем в опорном положении, поскольку преодолевается только инерция масс перемещающихся частей тела.

Следовательно, наиболее эффективно выполнять наибольший объем движений, составляющих фигуру прыжка в верхней части траектории полета - в конце восходящей и начале нисходящей ее ветвей, поскольку это требует меньших затрат усилий и позволяет спортсмену максимально проявлять скоростные качества, это придает легкость и эффективность исполнению прыжка.

Таким образом, оторвавшись от действия внутренних (мышечных) сил, спортсмен не может в полете изменить форму его траектории, количество движения центра массы своего тела, величину вращательного импульса N, созданного при отталкивании, так как в полете он представляет собой изолированную от внешних сил систему. Единственной внешней силой, действующей на спортсмена в полете, является сила тяжести.

Однако прыгун может управлять скоростью своего вращения в полете. Эта возможность основана на использовании закона сохранения вращательного импульса. Величина вращательного импульса определятся произведением угловой скорости на момент инерции тела и является величиной постоянной.

$$
\begin{gathered}
\mathrm{N}=\omega \cdot \mathrm{I}=\text { const } \\
\omega \text {-угловая скорость } \\
\text { I - момент инерции }
\end{gathered}
$$

Момент инерции - это сопротивление объекта любому изменению своего углового движения, представляющее собой распределение массы относительно оси вращения:

$$
I=\sum m \cdot r^{2}
$$

Поэтому спортсмен, изменяя величину момента инерции своего тела относительно оси вращения, может активно изменять величину угловой скорости. Изменения моментов инерции могут быть различными. Для условий вращения вокруг поперечной оси они могут меняться от наибольшего значения, соответствующего вытянутому положению с поднятыми над головой руками, до наименьшего значения, соответствующего положению группировки (рисунок 1). 


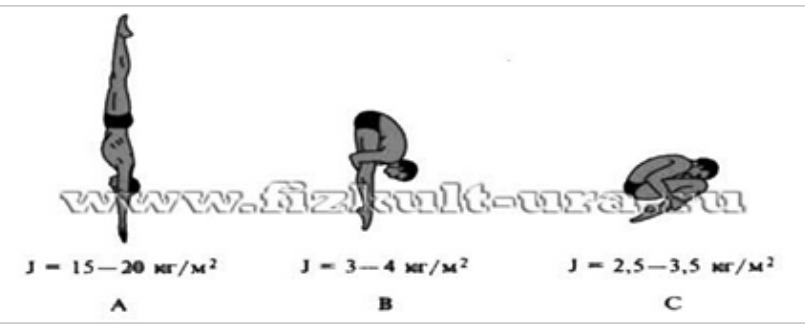

Рис. 1. Изменение момента инерции тела при прыжке в воду в зависимости от положения тела в полете:

A - прогнувшись; B - согнувшись; C - в группировке

Величина моментов инерции для главной поперечной оси колеблются от 15-20 кг/м в выпрямленном положении до 3-4 кг/м в положении группировки. Приведенные значения примерны и зависят от конституциональных особенностей и индивидуальных величин общих масс тела спортсменов. Однако для каждого отдельного спортсмена существенное значение имеет не абсолютная, а относительная величина изменения момента инерции его тела, которая изменяется в 3,75-6,7 раза. Другими словами, изменяя момент инерции, Спортсмена может в 3,75-6,7 раза увеличивать, а затем уменьшать скорость вращения своего тела.

Действия закона сохранения вращательного импульса проявляется и при перемещении мгновенных осей вращения.

\section{Выво}

Анализ литературы показал, что исследований направленных на изучение кинематических характеристик техники прыжков в воду недостаточно. Изучение техники сводилось в основном к описанию движений спортсменов при выполнении той или иной фазы прыжка. Отсутствуют данные о кинематических параметрах выполнения наиболее важной фазы прыжков в воду с трамплина - отталкивание и создание вращения тела.

\section{ЛИТЕРАТУРА}

1. Андреева Н.А., Ефимова С.П. Прыжки в воду: Учебное пособие для институтов физической культуры / Н.А. Андреева, С.П. Ефимова, Л.И. Ефимов, К.Ю. Данилов, Б.П. Клинченко, В.А. Северин, Л.Н. Тишина // под ред. С.П. Ефимовой - М.: «Физкультура и спорт», 1965 - 230с.

2. Водные виды спорта: Учебник для студ. высш. учеб. заведений / Н.Ж. Булгакова, М.Н. Максимова, М.Н. Маринич и др.; Под ред. Н.Ж. Булгаковой. М.: Издательский центр «Академия», 2003. - 320 с.

3. Распопова Е.А. Прыжки в воду: Учебник для вузов физической культуры/ Е.А. Распопова - М.: Физкультура, образование, наука, 2000 - $312 c$.

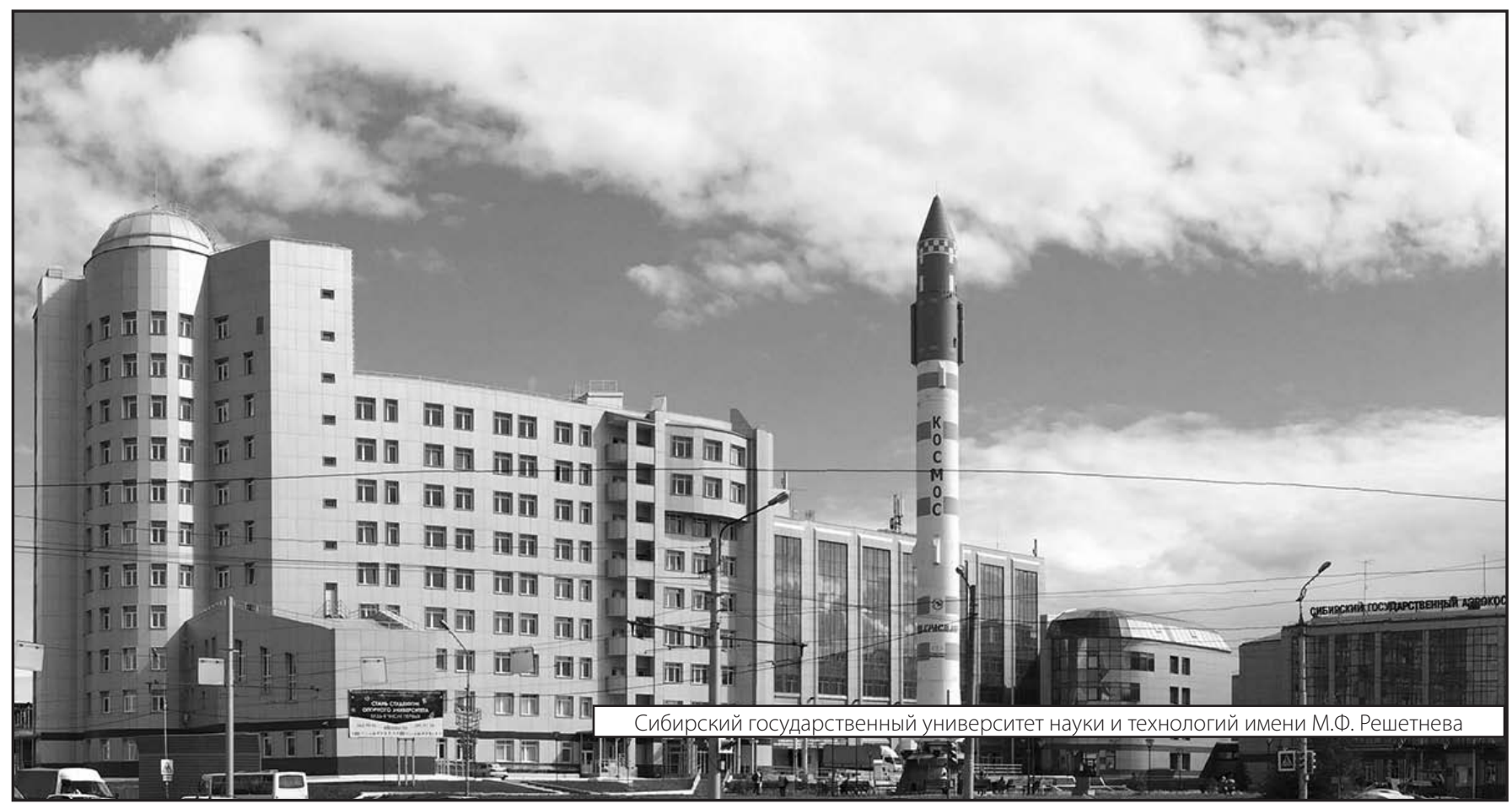

